\title{
Label-Free and Self-Signal Amplifying Molecular DNA Sensors Based on Bioconjugated Polyelectrolytes**
}

\author{
By Kangwon Lee, Laura K. Povlich, and Jinsang Kim*
}

Hybrid bio/-synthetic sensory conjugated polyelectrolytes were developed to achieve selective label-free detection of target oligonucleotides with amplified fluorescence signal in solution. A completely water soluble and highly fluorescent conjugated poly $(p$-phenyleneethynylene) (PPE) was rationally designed and synthesized as a signal amplifying unit and chemically modified with carboxylic functional groups at the ends of the polymer chains to bioconjugate with amine functionalized singlestranded oligonucleotides as a receptor using carbodiimide chemistry. This approach allows the functional groups on the polymers to be effectively linked to DNA without any damage to the conjugated $\pi$-system of the polymers. DNA detection results using the PPE-DNA hybrid system confirmed large signal amplification by means of efficient Förster energy transfer from the energy harvesting PPE to the fluorescent dye attached to the complementary analyte DNA. To realize label-free detection, we also connected a DNA molecular beacon to the newly developed conjugated polymer as a self-signaling molecular switch. A DNA detection study by using the resulting PPE-DNA beacon and single strand analyte DNAs showed not only signal-amplification properties but also self-signaling properties.

\section{Introduction}

Conjugated polymers (CPs), pioneered by Shirakawa et al., have a framework of alternating single and double carbon-carbon bonds and are emerging materials for many modern technologies. ${ }^{[1]}$ CPs have unique properties that are not exhibited by monomeric fluorophores such as amplified fluorescence through energy-harvesting, ${ }^{[2]}$ excellent one-dimensional energy transport of electrons or holes, ${ }^{[3]}$ and strong UV absorption. Among these properties, fluorescence is one of the most sensitive to environmental change and this allows conjugated polymers to be used as signaling reporter groups. ${ }^{[4]}$ In monomeric fluorophore based sensors, only the receptors bound with target analyte can contribute to the sensory signal, which is a simple summation of the fluorescence emission from each bound

[*] Prof. J. Kim, K. Lee

Department of Materials Science and Engineering, University of Michigan

Ann Arbor, MI 48109 (USA)

E-mail: jinsang@umich.edu

Prof. J. Kim, L. K. Povlich

Macromolecular Science and Engineering, University of Michigan Ann Arbor, MI 48109 (USA)

Prof. J. Kim

Chemical Engineering, University of Michigan

Ann Arbor, MI 48109 (USA)

Prof. J. Kim

Biomedical Engineering, University of Michigan Ann Arbor, MI 48109 (USA)

[**] J. K. gratefully acknowledges support from the National Science Foundation (BES 0428010) the UM College of Engineering startup fund. J. K. and K. L. also acknowledge Ilju Foundation for the Ilju scholarship. receptor. On the contrary, any single binding event between receptor and target causes a change in the electronic environment of a conjugated polymer chain, resulting in an alteration of the emission of the entire polymer chain. In addition, the target receptor group can be rationally designed and covalently connected to the CP main chain in order to give eminent selectivity. ${ }^{[5]}$ CPs have attracted great attention for sensor technologies including ion sensors, ${ }^{[6]} \mathrm{pH}$ sensors, ${ }^{[7]} \mathrm{TNT}$ sensors, ${ }^{[8]}$ temperature sensors, ${ }^{[9]}$ warfare agent sensors ${ }^{[10]}$ and even recently developed biosensors. ${ }^{[11,12]}$

A conjugated polyelectrolyte (CPE) is a $\pi$-conjugated polymer that contains charged side chains to give it water-solubility. ${ }^{[13]}$ The water-soluble pendent groups used most for CPEs are sulfonate $\left(\mathrm{SO}_{3}{ }^{-}\right)$, carboxylate $\left(\mathrm{CO}_{2}^{-}\right)$, and phosphate $\left(\mathrm{PO}_{4}{ }^{3-}\right)$ ions (negative) and quaternatry ammonium $\left(\mathrm{NR}_{3}{ }^{+}\right)$ ions (positive). Water-solubility of CPEs is difficult to achieve because of the hydrophobic nature of the CPE backbones and $\pi-\pi$ interactions between adjacent polymer main chains cause polymer aggregation. Even worse, it is almost impossible to redissolve a CPE in water once the polymer has been completely dried. Solving the problem of CPE aggregation in aqueous media remains a challenging task in many research groups. ${ }^{[14]}$ For several years we have been systematically investigating the relation between water-solubility and the chemical structure of CPEs. In our previous research, we synthetically prepared completely water soluble and highly emissive conjugated poly ( $p$-phenyleneethynylene) (PPE- $\mathrm{R}_{1}$ and $\mathrm{PPE}-\mathrm{R}_{1}-\mathrm{COOH}$, Fig. 1). ${ }^{[15]}$ We discovered that well-defined tuning of water-solubility can be achieved by precise control of the side chain shape and pendent ionic group of CPEs. Achieving the water solubility of CPEs should expand the applications of conjugated polymers to biological sensors for DNA and protein detection in aqueous media. By rendering largely amplified fluores- 

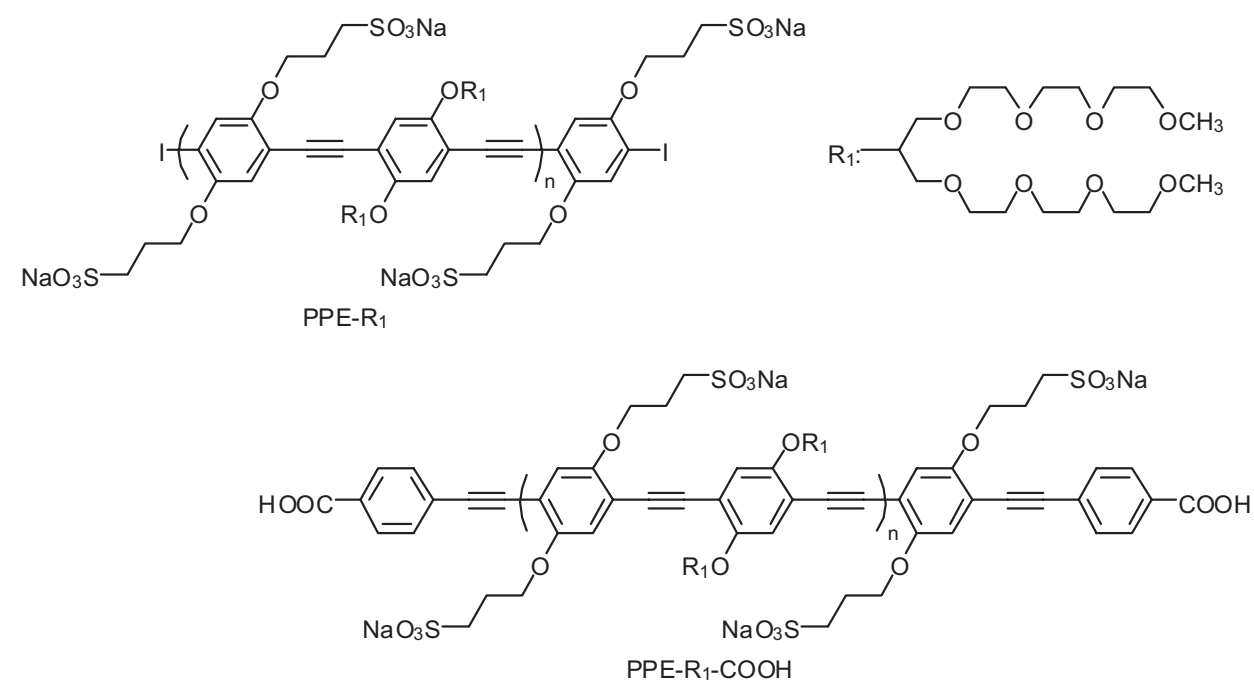

Figure 1. Chemical structure of PPE- $\mathrm{R}_{1}$ and PPE- $\mathrm{R}_{1}-\mathrm{COOH}$.

cence signal through the signal amplifying property of $\mathrm{CPs}$, trace amounts of target can be possibly detected.

Many research groups have reported signal amplifying DNA sensors using various types of CPEs. Leclerc et al. have explored positively charged poly(thiophene) based DNA detection systems on the basis of conformational perturbations of polymer main chains and ensuing color change. ${ }^{[16]}$ Bazan et al. used a fluorescence resonance energy transfer (FRET) mechanism to detect a target DNA through triplex formation of DNA/PNA or DNA/DNA with cationic poly(fluorene-cophenylene)s. ${ }^{[17]}$ These methodologies used charge-charge interactions between cationically charged CPE and negatively charged oligonucleotide without requiring any chemical functionalization of polymer probes. Tan et al. recently reported an effective method for covalent conjugation of an oligonucleotide molecule to PPE by in-situ polymerization of PPE in the presence of an oligonucleotide linked to a CPG support and achieved self-signal amplifying DNA detection. ${ }^{[18]}$ However, this system requires surfactants due to the limited solubility of the resulting polymer in water.

Herein, we describe a practical synthetic method for bio/-synthetic anionic poly(phenyleneethynylene)-DNA sensors for efficient self-signal amplifying DNA detection (Scheme 1) in aqueous solution. By using a simple carboiimide chemistry, PPE was successfully conjugated to DNA molecules by amide bond formation. The resulting single stranded DNA (ssDNA) coupled at the end of the polymer chains selectively hybridized with HEX (hexachlorofluorescein, a fluorescent dye)-labeled target complementary DNA. A large amount of fluorescence energy from the PPE was efficiently transferred to the target HEX-DNA upon DNA/DNA hybridization, resulting in large signal amplification. Therefore, the PPE-DNA hybrid based DNA detection system successfully showed large signal amplification through Förster type energy transfer mechanism (FRET). In addition, we also covalently connected the PPE with an oligonucleotide probe that has a quencher at the end. This oligonucleotide molecular beacon can form a hairpin-shape in buffer solutions resulting in the fluorescence quenching of the PPE but unfolds to form a DNA double helix upon addition of complementary DNA turning on the fluorescence emission of the PPE. Hence, in this molecular design the completely water-soluble and highly fluorescent conjugated polymer replaces a fluorescent dye of the conventional molecular beacon to allow label-free and self-signal amplifying detection of target DNA upon hybridization.

\section{Results and Discussion}

\subsection{Water Solubility of the CPE}

Water soluble PPE- $\mathrm{R}_{1}$ and its carboxylic acid-functionalized derivative (PPE- $\mathrm{R}_{1}-\mathrm{COOH}$ ) were previously reported in literature ${ }^{[15]}$ Homogeneous biological sensors must be water soluble or at least have entire compatibility with aqueous phase because most biological targets that we are interested in detecting exist in an aqueous environment. Another issue for sensor design is the need to develop fine selectivity to trace amounts of biological molecule. Therefore, it is indispensable for solutionstate sensors to be water-soluble and highly sensitive to the binding event between receptor and target molecule. However, the hydrophobicity of conjugated polymer backbones causes aggregation between polymer chains in water and restricts aqueous dissolution of the polymers. Even worse, if rigid and hydrophobic polymers are dried, they are extremely difficult to re-dissolve in water. Many groups have tried to de-aggregate the polymer chains by adding surfactant, however, this is not always the finest solution because, in some cases, surfactants may interfere with the sensing system. ${ }^{[20]}$ To fulfill the requirements mentioned above, we strived to make completely watersoluble and highly fluorescent conjugated polymers for to biological sensor applications. Almost all the PPE polymers we initially made showed aggregation or fluorescence quenching 


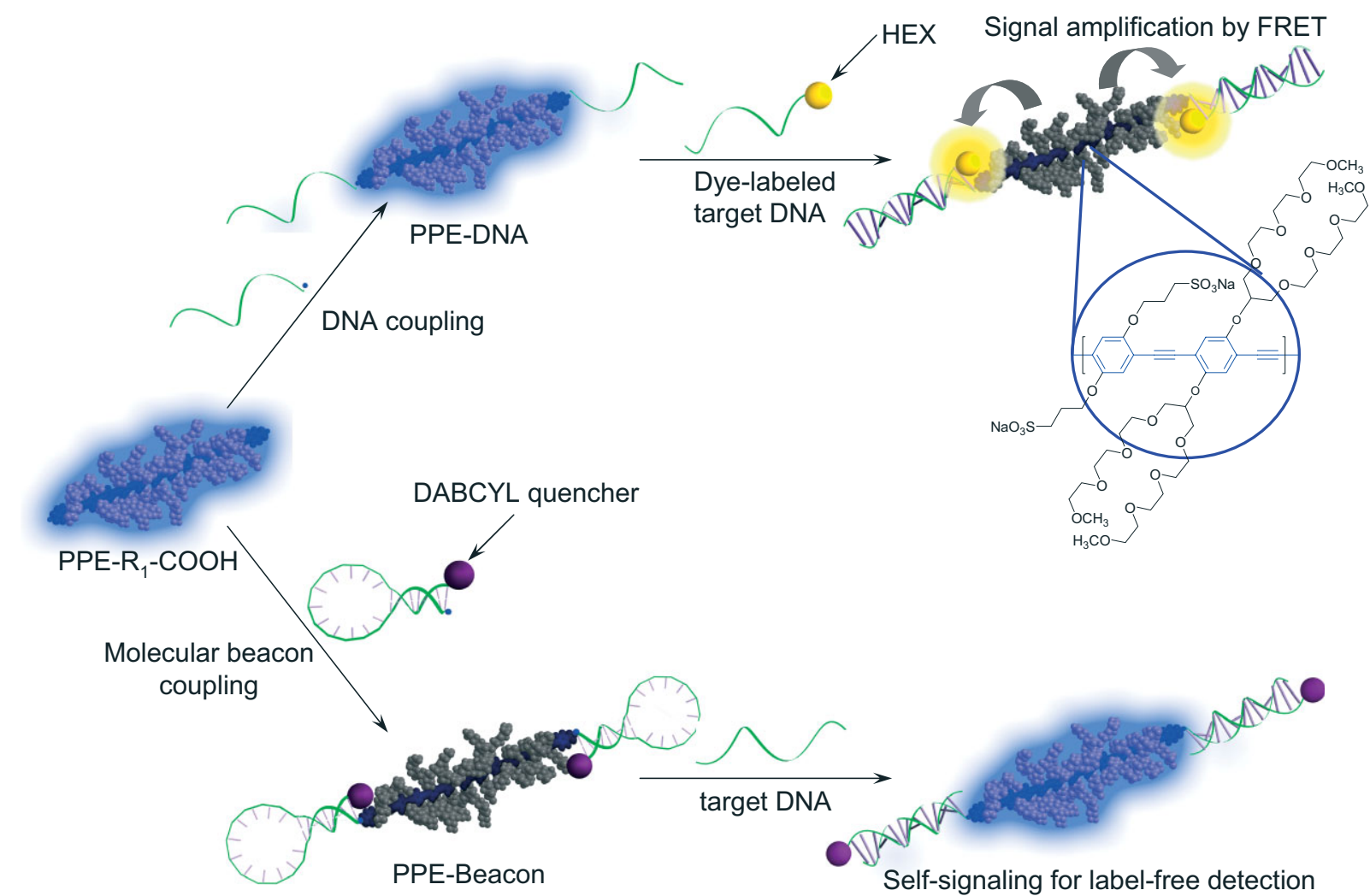

Scheme 1. Polymer-oligonucleotide bioconjugation to form PPE-DNA (top) to demonstrate signal amplifying property by FRET and PPE-DNA beacon (bottom), demonstrating self-signal amplifying label-free detection.

in water. ${ }^{[21]}$ Eventually, it was discovered that PPE- $\mathrm{R}_{1}-\mathrm{COOH}$ was completely soluble in water. The ionic side chain (sulfonic acid sodium salt) provides the polymer with water-solubility and the bulky ethylene oxide side chain prohibits the polymer chains from agglomerating by sheathing the hydrophobic backbone of the polymers. ${ }^{[22]}$ Fully dried PPE- $\mathrm{R}_{1}$ dissolves in pure water with a solubility exceeding approximately $1 \mathrm{mg} \mathrm{ml}^{-1}$ $(80 \mu \mathrm{M})$.

\subsection{Polymer-DNA Bioconjugation}

Conventional carbodiimide chemistry using EDC/sulfo-NHS catalyst offers a facile and simple method for the coupling of amino-functionalized oligonucleotides to the carboxlylic acid groups of the polymers. First we confirmed the reactivity of the carboxylic acid group at the end of PPE- $\mathrm{R}_{1}-\mathrm{COOH}$ by successfully attaching the PPE- $\mathrm{R}_{1}-\mathrm{COOH}$ to amine-fuinctionalized PS resins by carbodiimide chemistry. After the coupling reaction, the mixture solution was filtered to remove any unbound residual polymer in the solution. The filtrate solution showed very little fluorescence, which indicated that almost all the polymer was chemically bound to the PS resin implying the high reactivity of the chain-end carboxylic group. We applied the reactivity of the polymer toward amines to the covalent bioconjugation between the polymer and amine-functionalized oligonucleotides. The oligonucleotide used was $5^{\prime}-\mathrm{NH}_{2}-\mathrm{C}_{6}$-ACA CAT CAC GGA TGT-3' (ssDNA-NH ${ }_{2}$ ), with an amine group at the $5^{\prime}$ position. An excess amount of the DNA was added to the polymer solution to ensure binding of the polymer molecule to the amine. After the coupling reaction between the two molecules, polymer and oligonucleotide, it was possible to purify the excess unbound oligonucleotide by microcentrifugal washing, which can separate components with different molecular weights. The molecular weight of the 15 -sequence oligonucleotide is $4762.2 \mathrm{~g} \mathrm{~mol}^{-1}$ and the number average molecular weight of the PPE- $\mathrm{R}_{1}-\mathrm{COOH}$, which was characterized by ${ }^{1} \mathrm{H}$ NMR end-group analysis, is $13000 \mathrm{~g} \mathrm{~mol}^{-1}$. The molecular weight of the bioconjugated PPE-oligonucleotide molecule is approximately $22000 \mathrm{~g} \mathrm{~mol}^{-1}$, so a centrifugal filter with a molecular weight cut-off (MWCO) of 10000 is small enough to selectively remove the unbound oligonucleotide only. This has been confirmed by monitoring the change of the filtrate's UV absorbance $(260 \mathrm{~nm})$ after each washing time. Washing by centrifugation was repeated until there was no more change in UV absorbance. For the longer sequence hairpin oligonucleotides (5'- $\mathrm{NH}_{2}-\mathrm{C}_{6}$-ACA CAT CAC GGA TGT-3'), the bioconjugated polymer-beacon was also purified in the same manner but with a larger molecular weight cut-off microcentrifuge tube $\left(\mathrm{MWCO}=12000 \mathrm{~g} \mathrm{~mol}^{-1}\right)$. Bioconjugation between the polymer and DNA was confirmed by DNA gel electrophoresis. Nusieve agarose gel ( $4 \%$ ) was used to analyze the DNA-PPE bioconjugate after hybridization. In Figure 2, lane 1 has only 15 base DNA that was hybridized with its target complementary DNA. Ethidium bromide stained the double helix DNA and 


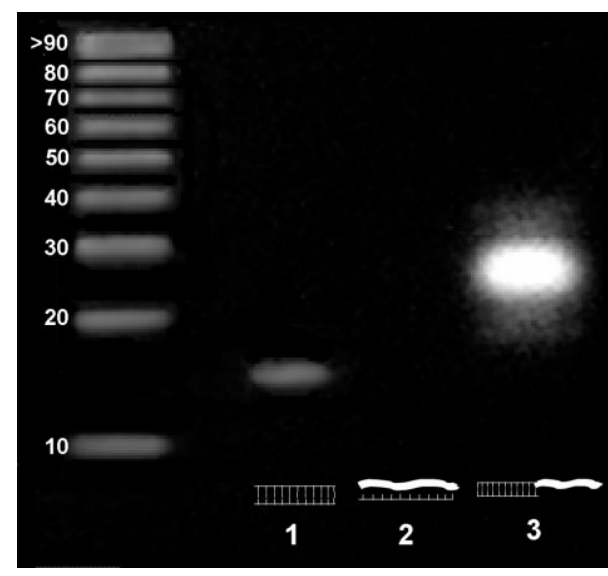

Figure 2. Gel electrophoresis of DNA (lane 1), PPE-R1-COOH (lane 2), and PPE-DNA (lane 3) in the presence of c-DNA.

shows the corresponding band. In lane $2, \mathrm{PPE}-\mathrm{R}_{1}-\mathrm{COOH}$ before DNA conjugation was mixed with target DNA as a negative control. No band is observed in lane 2 because PPE- $\mathrm{R}_{1^{-}}$ $\mathrm{COOH}$ does not have DNA bioconjugation and ensuing the absence of DNA double helix formation. In contrast, in lane 3, the PPE-DNA bioconjugate forms DNA double helix upon binding with the target DNA and shows the broad band in the higher molecular region. This indicates that polymer and DNA are successfully coupled since the new band has slower migration compared to DNA alone due to the large molecular weight of the polymer. The broad feature of the band is likely to be the result of the polydispersity of the polymer.

\subsection{Signal Amplification by Means of FRET}

Figure 3 , which was obtained in $6 \times$ SSPE buffer at concentrations used in the DNA hybridization protocols, shows the absorption and emission spectra of PPE- $\mathrm{R}_{1}-\mathrm{COOH}$ and $\mathrm{HEX}$ labeled DNA. After coupling the DNA and PPE- $\mathrm{R}_{1}-\mathrm{COOH}$, the absorption and emission of the resulting PPE-DNA did not show any significant changes from those of PPE- $\mathrm{R}_{1}-\mathrm{COOH}$.

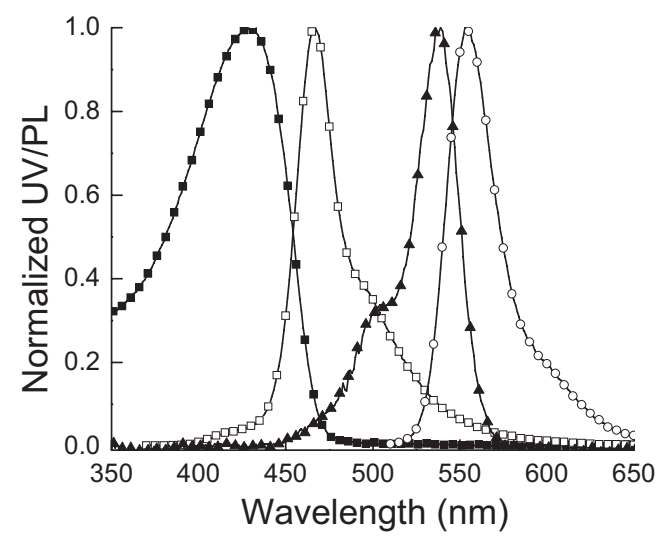

Figure 3. Normalized UV/PL spectra of PPE- $\mathrm{R}_{7}-\mathrm{COOH}$ and HEX: absorption ( $\square$ ) and emission $(\square)$ spectrum of PPE, absorption $(\boldsymbol{\Delta})$ and emission (O) spectrum of HEX.
The only difference was an increase in UV absorbance in the ca. $260 \mathrm{~nm}$ region, which is characteristic of the absorption of oligonucleotides indicating that oligonucleotide molecules were successfully bound to $\mathrm{PPE}-\mathrm{R}_{1}-\mathrm{COOH}$. The emission spectra of the polymers are narrow with well-defined $0-0$ bands at $\lambda_{\text {max }}=460 \mathrm{~nm}$ and do not show any aggregation bands. The absolute quantum yields of PPE- $\mathrm{R}_{1}$ and $\mathrm{PPE}-\mathrm{R}_{1}-\mathrm{COOH}$ in water, as analyzed by using an integrating sphere, were $53 \%$ and $45 \%$, respectively. We used the PPE-DNA (15 base) bioconjugate as a model in order to investigate if the FRET mechanism from the emissive PPE to the HEX works upon hybridization.

As shown by Förster, ${ }^{[23]}$ FRET is nominally the non-radiative transfer of energy from a donor to an acceptor molecule. Therefore, the signature of FRET is quenching of a high energy fluorophore followed by relatively high frequency light emission from an acceptor fluorophore. For this to occur, donor and acceptor molecules must be in close proximity (typically 1-10 nm). The FRET efficiency (F) is dependent on the inverse sixth power of the intermolecular separation, making it useful over distances comparable with the dimensions of biological macromolecules. In addition, the fluorescence spectrum of the donor must be overlapped with the absorption spectrum of the acceptor. As one can clearly see in Figure 3, there is an excellent overlap between the emission of PPE- $\mathrm{R}_{1}-\mathrm{COOH}$ and the absorption of HEX in the 450-600 nm range, which should make efficient FRET from PPE to HEX. Because the absorption spectra of the PPE and HEX are well separated selective excitation of PPE and HEX should be feasible for FRET study.

To demonstrate FRET, hybridization tests were conducted with HEX-labeled complementary ssDNA. The complementary ssDNA used in the study was HEX-DNA (5'-HEX-ACA CAT CAC GGA TGT-3'), with HEX (hexachlorofluorescein) at the 5' position. FRET experiments for HEX-DNA were carried out in $6 \times$ SSPE buffer and the results are shown in Figure 4. After hybridization, the PPE-DNA/DNA-HEX complex was selectively excited by $365 \mathrm{~nm}$ wavelength UV irradiation, which is not significantly absorbed by HEX. During this excita-

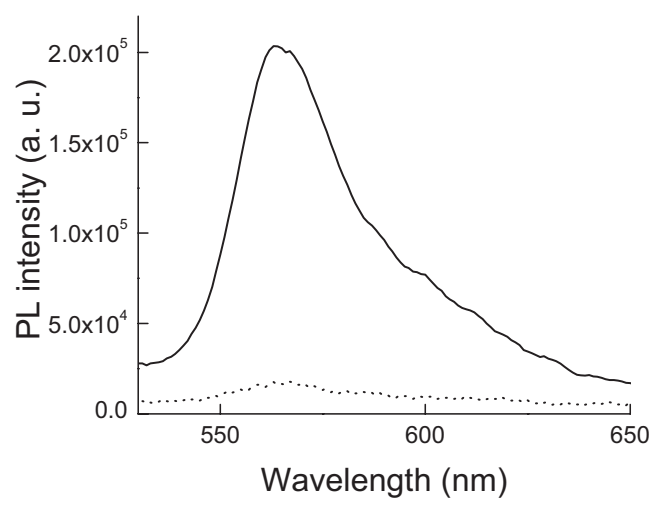

Figure 4. Emission spectra of PPE-DNA $\left(1.0 \times 10^{-7} \mathrm{M}\right)$ upon hybridization with a complementary target HEX-DNA $\left(4.0 \times 10^{-7} \mathrm{M}\right)$ when HEX was directly excited at $500 \mathrm{~nm}$ (dotted line) and when the PPE was excited at $365 \mathrm{~nm}$ (solid line) followed by FRET to HEX. 
tion experiment the fluorescence intensity from PPE was decreased and emission from HEX at $561 \mathrm{~nm}$ was largely increased as demonstrated in Figure 5. ${ }^{[24]}$ The fluorescence intensity of HEX of the PPE-DNA/DNA-HEX complex was amplified more than 13 times compared to the emission intensity of the complex when HEX was directly excited at $500 \mathrm{~nm}$

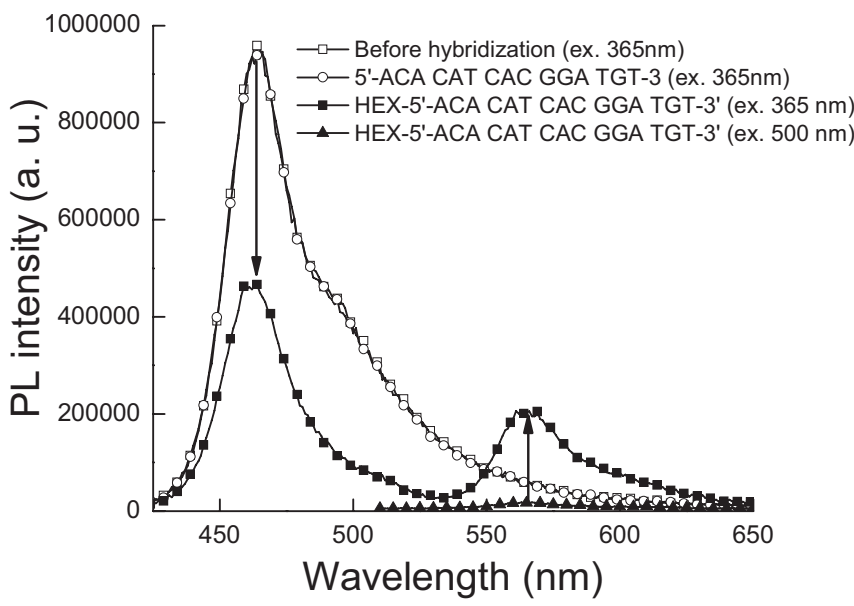

Figure 5. Comparison of PL change before $(\square)$ and after hybridization between HEX-labeled complementary target (excitation at $365 \mathrm{~nm} \mathbf{\square}$; at $500 \mathrm{~nm} \mathrm{\Delta}$ ) and non-labeled complementary target $(\bigcirc)$.

as shown in Figures 4 and 5. The energy harvesting/transport properties of PPE after hybridization make it possible to achieve a highly amplified fluorescence signal by direct energy flow from the polymer to the dye. Therefore, these results confirmed the signal amplification of HEX by energy transferred from PPE, indicating that our strategy of FRET from the PPE to dye was effective upon hybridization.

Control experiments were also performed with the same sequence of complementary DNA but without HEX (Fig. 5). Polymer emission at $460 \mathrm{~nm}$ did not show any change after hybridization with non-labeled target DNA, denoting that FRET is not observed in the absence of an energy acceptor molecule. This supports our interpretation that effective FRET from the polymer to HEX occurs upon hybridization. We also prepared completely water-soluble and cationically charged poly(phenyeleneethynylenes) (Fig. 6) as a control. The control polymer was mixed with HEX-labeled DNA to determine if FRET oc- curs from the polymer to HEX because of the attraction between the two oppositely charged fluorophores. After adding DNA, the fluorescence intensity from PPE significantly decreased. However, we observed very little signal amplification around HEX emission (Fig. 7). Fluorescence quenching of the polymer or HEX is believed to be due to the guanine $(\mathrm{G})$

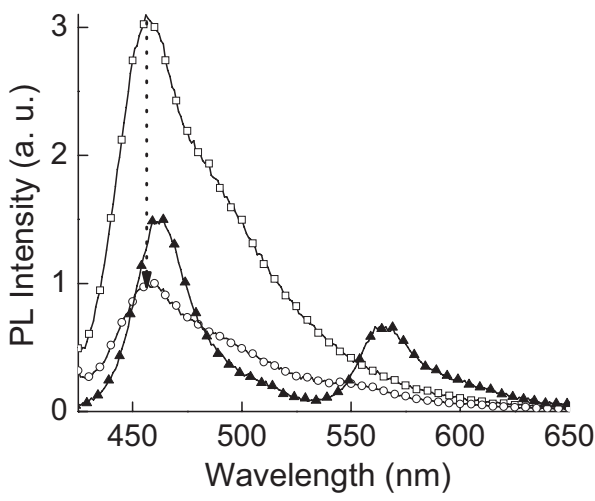

Figure 7. Comparison PL enhancement of HEX before $(\square)$ and after $(\bigcirc)$ adding HEX-labeled ssDNA in positively charged PPE (PPE-N $\left(\mathrm{CH}_{3}\right)_{3}^{+}$). Compared with the PPE-DNA/DNA-HEX complex case $(\boldsymbol{\Delta})$, increment of HEX emission in PPE-N $\left(\mathrm{CH}_{3}\right)_{3}{ }^{+}$/DNA-HEX is negligible.

group in the oligonucleotides. ${ }^{[25]}$ Since $\mathrm{G}$ is the most electrondonating base of all four bases, the fluorescence drop can take place via electron transfer. ${ }^{[25]}$ Also, the instability of DNA/ polymer complex due to non-specific binding provides more conformational degrees of freedom to $\mathrm{G}$, resulting in a fluorescence drop of PPE and/or HEX. Even though the two fluorophores are oppositely charged, the bulky side chains of PPE- $R_{1}$ likely inhibit HEX from approaching the PPE backbone at a proximity close enough to see effective FRET. These results indicate that effective FRET from the polymer to HEX can be only achieved by stable polymer-DNA complex formation through hybridization with target complement at the polymer chain ends and not by simply mixing the two fluorophores. We endeavored to trace the emission source of the HEX molecules after hybridization. Figure 8 shows the excitation spectrum of the post-hybridized PPE-DNA/DNA-HEX complex and HEX-labeled DNA only. The result reveals that HEX emission originated not from the HEX itself but from the PPE emission.

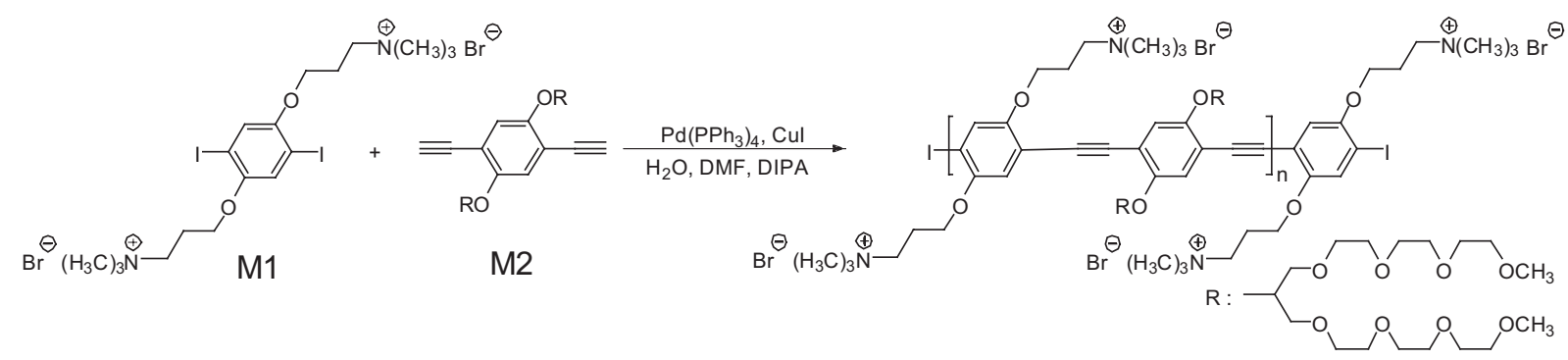

Figure 6. Chemical structure of positively charged PPE (PPE-N $\left.\left(\mathrm{CH}_{3}\right)_{3}{ }^{+}\right)$. 


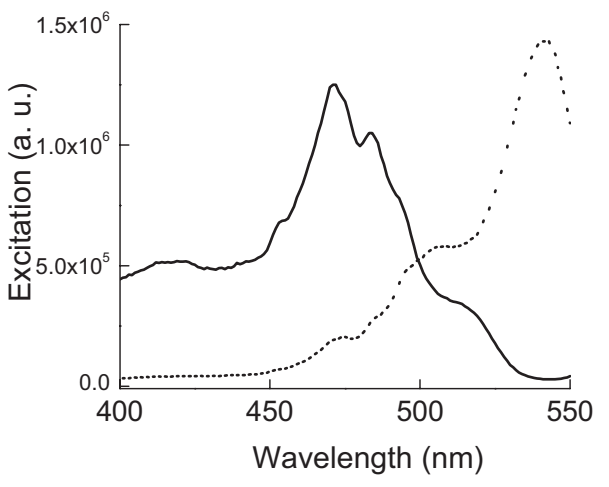

Figure 8. Excitation spectrum of PPE-DNA/HEX-DNA (solid) and HEX-labeled DNA only (dotted) corresponding to the emission wavelength of $556 \mathrm{~nm}$.

This result also demonstrates that FRET from the conjugated PPE to HEX was accomplished.

\subsection{Self-Signaling Design for Label-Free Detection}

Successful FRET by PPE-DNA/HEX-DNA hybridization allowed us to expand the sensor system to polymer-beacon conjugates. The molecular beacon, developed by Tyagi et al, is a self-signaling probe that eliminates the cost and time consuming procedures of DNA fluorescence labeling. ${ }^{[26]}$ A traditional molecular beacon is a hairpin ssDNA in which a fluorescence dye and a quencher molecule located at opposite ends of the hairipin are in close contact. In a hairpin-shaped state (closed form), the stem keeps these two moieties in a close proximity to each other and fluorescent energy from the fluorophore is absorbed by the quencher through a FRET mechanism. However, when a target complementary ssDNA is introduced into the solution, hybridization opens the hairpin, thus moving the fluorescent dye away from the quencher and allowing the dye to emit a fluorescence signal. The rigidity and the length resulting from DNA double helix formation prevents the fluorophore and the quencher from being in close proximity. We applied the molecular beacon concept to our sensor design by replacing the conventional dye with conjugated PPE. Conjugated polymer can be considered a macromolecular chromophore that operates as a one-dimensional wire-like molecule that amplifies the fluorescence signal and the two molecular beacons at the ends of the polymer are two switches that turn off and on the amplified fluorescence signal of the polymer. In closed form, polymer fluorescence is completely quenched through the amplified quenching mechanism of the polymer. Fluorescent sensory signal amplification is induced upon opening of the hairpin by DNA/DNA hybridization, thus providing high sensitivity and label-free detection.

We have directly bioconjugated PPE- $\mathrm{R}_{1}-\mathrm{COOH}$ to an amine functionalized oligonucleotide attached to a quencher by standard carbodiimide coupling and purified them in the same manner as used for the PPE-HEX experiments. A 25 base $\left(5^{\prime}-\mathrm{NH}_{2}-\mathrm{CGC}\right.$ TCG AAG GAG GAA GGA GGG AGC G -DABCYL-3') oligonucleotide that forms a stem and loop structure was used in the reaction. The 15-mer loop of the beacon used for these studies was designed to bind specifically to a sequence in the left side of the TC1 tract of the human c-Src proto-oncogene. ${ }^{[27]}$ According to theoretical calculations, this oligonucleotide sequence forms a stable hairpin $\left(\mathrm{d} G=-4.6 \mathrm{kcal} \mathrm{mol}^{-1}\right){ }^{[28]} \quad 4-(4-($ dimethylamino$)$ phenyl-azo)benzoic acid) (DABCYL) was used as the quencher due to the good overlap of its UV absorption spectrum $\left(\lambda_{\max }=478 \mathrm{~nm}\right)$ with PPE emission. After purifying the PPE-DNA-DABCYL beacon with centrifugal washing, UV absorbance from the PPE-DNA-DABCYL solution shows a shoulder at 460-500 nm, a typical characteristic of DABCYL absorbance, revealing that PPE was successfully conjugated to $\mathrm{NH}_{2} \mathrm{DNA}$ DABCYL (Fig. 9).

Figure 10 shows the fluorescence enhancement of PPE from post-hybridization with a series of DNA molecules including complementary ssDNA (5'-CGC TCC CTC CTT CCT CCT TCT TT-3'), 1-mismatch ssDNA (5'- CGC TCC CTC CAT

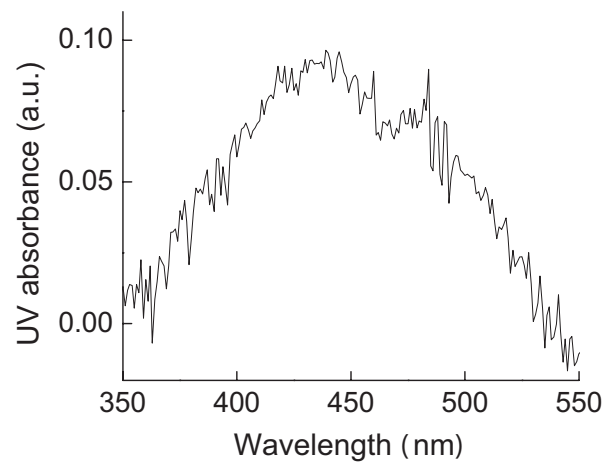

Figure 9. UV absorbance of PPE-DNA beacon $\left(1.0 \times 10^{-6} \mathrm{M}\right)$.

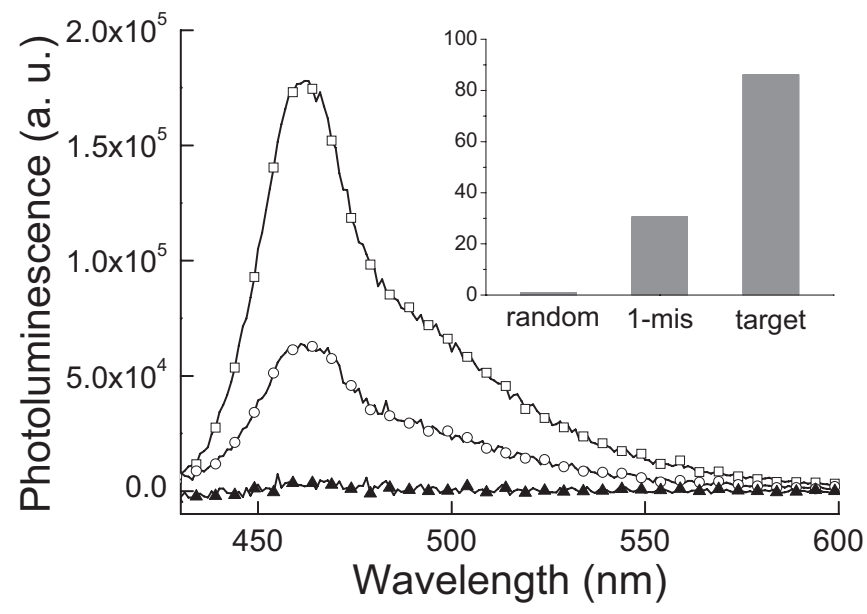

Figure 10. Overall fluorescence enhancement in polymer-beacon $\left(1.0 \times 10^{-6} \mathrm{M}\right)$ after hybridization: complementary ssDNA $\left(4 \times 10^{-6} \mathrm{M}, \square\right)$, 1-mismatch $(\bigcirc)$, non-complementary $\operatorname{ssDNA}(\boldsymbol{\Delta})$, Excitation wavelength was $420 \mathrm{~nm}$. Measurements were performed in Tris- $\mathrm{HCl}$ buffer (Tris- $\mathrm{HCl}$ $20 \mathrm{~mm}, \mathrm{NaCl} 50 \mathrm{~mm}, \mathrm{MgCl}_{2} 5 \mathrm{~mm}$, EDTA $2 \mathrm{~mm}$ ). All curves are background (prehybridization) subtracted. Inset: Normalized fluorescence increase in 1-mismatch and perfect target DNA with respect to the emission in non-complementary DNA. 
CCT CCT TCT TT-3'), and noncomplementary ssDNA (5'GTG AGG GAG GAA GTA AAA AGA TT-3'). The hybridization experiments were conducted in a $20 \mathrm{~mm}$ Tris- $\mathrm{HCl}$ buffer $(\mathrm{pH}=8.0)$. The fluorescence intensity in the presence of target DNA was almost two orders of magnitude higher than the fluorescence intensity in the presence of the non-complementary target (Fig. 10, inset). Polymer fluorescence was quenched in the closed form as the fluorescence energy of the polymer was effectively absorbed by DABCYL. Opening of the beacon loop through hybridization with complementary ssDNA caused DABCYL to move far away from PPE, resulting in prevention of FRET from PPE to DABCYL and the restoration of the polymer emission. The results demonstrate that the PPE-DNA beacon can provide not only signal amplification but also self-signaling property.

\section{Conclusion}

We developed hybrid bio/-synthetic sensory conjugated polymers to selectively and sensitively detect target DNAs in aqueous solution. A completely water-soluble and highly emissive conjugated poly( $p$-phenyleneethynylene) (PPE) was synthesized and covalently bonded to amine functionalized DNA through chain-end modification. Upon DNA/DNA hybridization the PPE-DNA hybrid system demonstrated efficient Förster energy transfer from PPE to the fluorescent dye attached to the complementary DNA. A large signal amplification through the use of engineered conjugated polymers was convincingly demonstrated. We also bioconjugated a DNA molecular beacon to a newly developed conjugated polymer to achieve label-free and signal-amplifying detection of target DNAs. The results presented in this contribution can give a design principle to develop completely water-soluble and highly emissive conjugated polymers and their bioconjugation with biological molecules for the development of high performance synthetic/bio-hybrid molecular biosensors and functional materials.

\section{Experimental}

Materials and Methods: The synthesis and characterization of PPE- $\mathrm{R}_{1}$ and PPE- $\mathrm{R}_{1}-\mathrm{COOH}$ have been reported previously [15]. The polymer was purified by dialysis against deionized water (molecular weight cut off $=14400 \mathrm{~g} \mathrm{~mol}^{-1}$ ), lyophilized to dry the polymer, and it was stored in the dried state at $4{ }^{\circ} \mathrm{C}$. We tried to investigate the molecular weight of polymer using polystyrene-based GPC in DMF. However, the result was inflated and unreliable because the rigid rod backbone of the PPE resulted in a very large hydrodynamic volume. The numberaveraged molecular weight $\left(M_{\mathrm{n}}\right)$ of the functionalized PPE $\left(\mathrm{PPE}-\mathrm{R}_{1^{-}}\right.$ $\mathrm{COOH}$ ), confirmed by ${ }^{1} \mathrm{H}-\mathrm{NMR}$ end-group analysis, was 13000 . The polymer solution was diluted as needed to prepare solutions used for spectroscopic experiments. Final concentrations of the diluted PPE- $\mathrm{R}_{1}$ $\mathrm{COOH}$ solutions were determined on the basis of polymer repeat unit concentrations. All of the oligonucleotides were purchased from Integrated DNA Technologies, Inc. (Coralville, IA) and used without further purification. EDC (1-ethyl-3-[3-dimethylaminopropyl]carbodiimide hydrochloride) and sulfo-NHS were purchased from Fluka, Inc. and Pierce, Inc. respectively and used as received. Polymer-DNA bio- conjugation samples were prepared by initially determining the DNA concentrations using standard UV absorption measurements with $200 \mu \mathrm{L}$ samples. Microcentrifugal units for separation of unbound oligonucleotides were used with two molecular weight cut-offs available: 10000 (purchased from Millipore Co), 12000 (purchased from Whatman). Microcentrifugations were conducted with Eppendorf Minispin at $13400 \mathrm{rpm}(12100 \times \mathrm{G})$.

Polymer Synthesis for PPE-N $\left(\mathrm{CH}_{3}\right)_{3}{ }^{+}$: The synthesis and characterization of M1 and M2 have been reported previously [19]. A $50-\mathrm{ml}$ Schlenk flask equipped with a stir bar was charged with M1 (44.0 mg, $62.0 \mu \mathrm{mol}, 1$ equiv. $), \mathrm{M} 2(55.0 \mathrm{mg}, 62.0 \mu \mathrm{mol}, 1$ equiv. $)$, and copper(I) iodide $(0.35 \mathrm{mg}, 1.86 \mu \mathrm{mol}, 0.03$ equiv.). The flask was placed under argon atmosphere and tetrakis(triphenylphodphine)palladium (0) ( $2.15 \mathrm{mg}, 1.86 \mu \mathrm{mol}, 0.03$ equiv.) and DMF $(1 \mathrm{ml})$ were added. Degassed diionized water $(1 \mathrm{ml})$ and diisopropylamine $(1 \mathrm{ml})$ were successively added to the mixture by cannular transfer and degassed by argon purging and vacuum recycles several times. The mixture was stirred at $55^{\circ} \mathrm{C}$ for $48 \mathrm{~h}$. The cooled polymer solution was filtered, concentrated, and precipitated in acetone and tetrahydrofuran. Then the compound was dissolved in diionized water $(20 \mathrm{ml})$ and dialyzed (Spectra/Por ${ }^{\circledR}$, Spectrum Laboratories, Inc., 12-14000 MWCO) against several changes of deionized water for $2 \mathrm{~d}$. Lyophilization of the resulting yellow-orange solution gave PPE-N $\left(\mathrm{CH}_{3}\right)_{3}{ }^{+}$as a yellow-brown fiber. ${ }^{1} \mathrm{H}$ NMR $\left(500 \mathrm{MHz}, \mathrm{D}_{2} \mathrm{O}\right) \delta 7.33(\mathrm{~s}, 2 \mathrm{H}), 7.23(\mathrm{~s}, 2 \mathrm{H}), 4.56(\mathrm{~m}, 2 \mathrm{H}), 4.15$ (t, 4H), $3.73(\mathrm{~m}, 4 \mathrm{H}), 3.65-3.38$ (broad $\mathrm{m}, 48 \mathrm{H}), 3.37(\mathrm{~m}, 8 \mathrm{H}), 3.17(\mathrm{~s}$, $12 \mathrm{H}), 3.00(\mathrm{~s}, 18 \mathrm{H}), 2.26(\mathrm{t}, 4 \mathrm{H})$; Molecular weight by NMR end-analysis $=14000$.

Photophysical Experiments: UV/Vis absorption spectra of the solutions were obtained on a Cary UV50 UV/Vis spectrometer (Varian, Inc.). Steady-state fluorescence of the polymer and dye was recorded on a PTI QuantaMaster spectrofluorometer ${ }^{\mathrm{TM}}$ with a xenon lamp and a detector at an angle 90 degree. The absolute quantum yield of the polymer was measured with excitation at $365 \mathrm{~nm}$ in deionized water $\left(1 \mathrm{mg} \mathrm{L}^{-1}\right)$ using an integrating sphere attached to the same spectrofluorometer.

Polymer-Oligonucleotide Bioconjugation: PPE- $\mathrm{R}_{1}-\mathrm{COOH}$ (0.13 mg), EDC (0.019 mg), and sulfo-NHS (0.0217 mg) were dissolved in $15 \mu \mathrm{l}$ of DI water and incubated for $30 \mathrm{~min}$ in a dark room at room temperature. $1 \mathrm{~mm}(50 \mu \mathrm{l})$ of amino-functionalized 15-base DNA (5'-ACA TCC GTG ATG TGT-3'- $\mathrm{NH}_{2}-3^{\prime}$ ) was added to the polymer solution and the solution was stirred for $2 \mathrm{~h}$. Unbound oligonucleotides from the PPE-DNA solution were removed by centrifugal washing with DI water several times using microcentrifuge tube $(\mathrm{MWCO}=10000)$ until no change in characteristic UV absorbance $(260 \mathrm{~nm})$ from the filtrate solution was observed. After filtering, the polymer-DNA bioconjugate solution was lyophilized to allow preservation in a dried state at $-20^{\circ} \mathrm{C}$. Coupling of DNA beacon to PPE- $\mathrm{R}_{1-}$ $\mathrm{COOH}$ was also achieved in the same manner as the polymer-15-base DNA bioconjugate. Amine-functionalized oligonucleotides with DABCYL as a quencher $\left(5^{\prime}-\mathrm{NH}_{2}-\mathrm{C}_{6}\right.$-CGC TCG AAG GAG GAA GGA GGG AGC G-DABCYL-3') were used in the coupling reaction. Microcentrifuge tubes $(\mathrm{MWCO}=12000)$ were used for the purification of polymer-beacon bioconjugates.

Analysis of Polymer-DNA Bioconjugates Formation by Gel Electrophoresis: To an each DNA, polymer, and polymer-DNA complex solution $4.8 \mu \mathrm{g}$ of complementary DNA (c-DNA, $15 \mathrm{bp}$ ) was added. The mixture was diluted with $6 \times$ SSPE buffer to a final c-DNA concentration of $50 \mu \mathrm{g} \mathrm{mL}^{-1}$, followed by incubation for $2 \mathrm{~h}$ at room temperature. The mixture was then analyzed by running it on a $4 \%$ agarose gel (Nusieve ${ }^{\circledR}$ 3:1 Agarose, Cambrex Bio Science Rockland, Inc.) in 1× phosphate buffer $(0.89 \mathrm{M}$ Tris base, $0.89 \mathrm{M}$ boric acid, and $0.02 \mathrm{M}$ EDTA, $\mathrm{pH}=8.3)$ at a constant voltage $(60 \mathrm{~V})$ for $90 \mathrm{~min}$. The gel was then stained with ethidium bromide to visualize the DNA bands. Images were captured with a CCD camera in fluorescence mode with a band pass filter of $630 \mathrm{~nm}$ to remove fluorescence $(460 \mathrm{~nm})$ from polymer emission.

Hybridization Test: All DNA hybridization tests were conducted at $25^{\circ} \mathrm{C}$. To $1.0 \times 10^{-7} \mathrm{M}$ polymer-DNA in $6 \times \mathrm{SSPE}(900 \mathrm{~mm}$ sodium chloride, $60 \mathrm{~mm}$ sodium hydrogen phosphate, 6 mм EDTA, pH 7.4) buffer solution, $4 \times 10^{-7} \mathrm{M}$ of HEX-labeled ssDNA (5'-HEX-ACA CAT CAC 
GGA TGT-3') was added. FRET tests were performed by checking UV absorbance and PL emission changes before and after hybridization upon excitation at $365 \mathrm{~nm}$ or $500 \mathrm{~nm}$. In the polymer beacon case, Tris- $\mathrm{HCl}$ buffer (Tris- $\mathrm{HCl} 20 \mathrm{~mm}, \mathrm{NaCl} 50 \mathrm{~mm}, \mathrm{MgCl}_{2} 5 \mathrm{~mm}$, EDTA $2 \mathrm{~mm}$ ) was used as the hybridization media. 2 equimolar amounts $\left(4 \times 10^{-6} \mathrm{M}\right)$ of target DNA $\left(5^{\prime}\right.$-CGC TCC CTC CTT CCT CCT TCT TT- $3^{\prime}$ ) were added to the polymer-DNA beacon solutions for which the concentration $\left(1 \times 10^{-6} \mathrm{M}\right)$ was determined by the UV absorption. Random sequence DNA (5'-GTG AGG GAG GAA GTA AAA AGA TT$\left.3^{\prime}\right)$ and 1-mismatch (5'-CGC TCC CTC CAT CCT CCT TCT TT-3') tests were also done in the same manner.

Received: February 21, 2007 Published online: August 28, 2007

[1] H. Shirakawa, E. J. Louis, A. G. MacDIarmid, C. K. Chiang, A. J. Heeger, J. Chem. Soc. Chem. Commun. 1977, 578.

[2] a) J. Kim, D. T. McQuade, A. Rose, Z. Zhu, T. M. Swager, J. Am Chem. Soc. 2001, 123, 11 488. b) T. Sato, D.-L. Jiang, T. Aida, J. Am. Chem. Soc. 1999, 121, 10658 . c) A. P. H. J. Schenning, E. Peeters, E. W. Meijer, J. Am. Chem. Soc. 2000, 122, 4489. d) M. R. Pinto, K. S. Schanze, Proc. Natl. Acad. Sci. USA 2004, 101, 7505. e) L. A. J. Chrisstoffels, A. Adronov, M. J. Fréchet, Angew. Chem. Int. Ed. 2000, 39, 2163. f) H.-A. Ho, M. Boissinot, M. G. Gergeron, G. Corbeil, K. Doré, D. Boudreau, M. Leclerc, Angew. Chem. Int. Ed. 2002, 41, 1548. g) J.-L. Brédas, D. Beljonne, V. Coropceanu, J. Cornil, Chem. Rev 2004, 104, 4971. h) M. A. Baldo, D. F. O’Brien, Y. You, A. Shoustikoy, S. Sibley, M. E. Thompson, S. R. Forrest, Nature 1998, 395, 151.

[3] a) A. Kraft, A. C. Grimsdale, A. B. Holmes, Angew. Chem. Int. Ed 1998, 37, 402. b) R. H. Friend, R. W. Gymer, A. B. Holmes, J. H. Burroughes, R. N. Marks, C. Taliani, D. D. C. Bradley, D. A. DosSantos, J.-L. Brédas, M. Logdlund, W. R. Salaneck, Nature 1999, 397, 121. c) Y. Cao, I. D. Parker, G. Yu, C. Zhang, A. J. Heeger, Nature 1999 397, 414. d) G. Klarner, M. H. Davey, W. D. Chen, J. C. Scott, R. D. Miller, Adv. Mater. 1998, 10, 993. e) F. Huang, L. T. Hou, H. B. Wu, W. H. Wang, H. L. Shen, W. Cao, W. Yang, Y. J. Cao, J. Am. Chem. Soc. 2004, 126, 9845. f) R. M. Jones, T. S. Bergstedt, D. W. McBranch, D. G. Whitten, J. Am. Chem. Soc. 2001, 123, 6726. g) C. A. Cutler, M. Bouguettaya, J. R. Reynolds, Adv. Mater. 2002, 14, 684. h) J. J. M. Halls, J. Cornil, D. A. Santos, R. Silbey, D. H. Hwang, A. B. Holmes, J.-L. Brédas, R. H. Friend, Phys. Rev. B 1999, 60, 5721. i) D. M. Guldi, A. Swartz, C. Luo, R. Gómez, J. Segura, N. Martín, J. Am. Chem. Soc 2002, 124, 10875. j) A. P. Kulkarni, C. J. Tonzola, A. Babel, S. A. Jenekhe, Chem. Mater. 2004, 16, 4556

[4] a) N. J. Turro, Modern Molecular Photochemistry, University Science Books, Sausalito, CA 1991. b) J. W. Hong, W. L. Hemme, G. E. Keller, M. T. Rinke, G. C. Bazan, Adv. Mater. 2006, 18, 878. c) J. H. Wosnick, T. M. Swager, Curr. Opin. Chem. Biol. 2000, 4, 715.

[5] For leading references: a) D. T. McQuade, A. E. Pullen, T. M. Swager, Chem. Rev. 2000, 100, 2537. b) T. M. Swager, Acc. Chem. Res. 1998, 31, 201. c) P. S. Heeger, A. J. Heeger, Proc. Natl. Acad. Sci. USA 1999, 96, 12219 .

[6] a) J. Kim, D. T. McQuade, S. K. McHugh, T. M. Swager, Angew Chem. Int. Ed. 2000, 39, 3868. b) M. R. Pinto, B. M. Kristal, K. S Schanze, Langmuir 2003, 19, 6523. c) M. J. Marsella, T. M. Swager, J. Am. Chem. Soc. 1993, 115, 12214. d) B. S. Harrison, M. B. Ramey, J. R. Reynolds, K. S. Schanze, J. Am. Chem. Soc. 2000, 122, 8561. e) L. H. Chen, D. McBranch, R. Wang, D. Whitten, Chem. Phys. Lett. 2000, 330, 27. f) D. L. Wang, J. Wang, D. Moses, G. C. Bazan, A. J. Heeger, J. H. Park, Y. W. Park, Synth. Met. 2001, 119, 587.

[7] a) D. T. McQuade, A. H. Hegedus, T. M. Swager, J. Am. Chem. Soc 2000, 122, 12 389. b) J. Song, J. S. Cisar, C. R. Bertozzi, J. Am. Chem Soc. 2004, 126, 8459. c) E. Shoji, M. S. Freund, J. Am. Chem. Soc. 2001, 123, 3383

[8] a) J. S. Yang, T. M. Swager, J. Am. Chem. Soc. 1998, 120, 5321. b) J. S. Yang, T. M. Swager, J. Am. Chem. Soc. 1998, 120,11864. c) Y. Liu, R. C. Mills, J. M. Boncella, K. S. Schanze, Langmuir 2001, 17, 7452.
[9] K. Kuroda, T. M. Swager, Macromolecules 2004, 37, 716

[10] a) I. A. Levitsky, S. G. Krivoshlykov, J. W. Grate, J. Phys. Chem. B 2001, 105, 8468. b) S.-W. Zhang, T. M. Swager, J. Am. Chem. Soc. 2003, 125,3420 .

[11] For references of conjugated polymer based DNA sensors, see; a) ref 2(f). b) B. S. Gaylord, A. J. Heeger, G. C. Bazan, Proc. Natl. Acad. Sci. USA 2002, 99, 10 954. c) K. P. R. Nilsson, O. Inganäs, Nat. Mater. 2003, 2, 419. d) C.-C. Pun, K. Lee, H.-J. Kim, J. Kim, Macromolecules 2006, 39, 7461. e) K. Lee, J.-M. Rouillard, T. Pham, E. Gulari, J. Kim, Angew. Chem. Int. Ed. 2007, 46, 4667.

[12] For conjugated polymer based peptide or protein sensors, see; a) S. Wang, G. C. Bazan, Adv. Mater. 2003, 15, 1425. b) L. Chen, D. W. McBranch, H. Wang, R. Helgeson, F. Wudl, D. G. Whitten, Proc. Natl. Acad. Sci. USA 1999, 96, 12287. c) J. H. Wosnick, C. M. Mello, T. M. Swager, J. Am. Chem. Soc. 2005, 127, 3400.

[13] M. R. Pinto, K. S. Schanze, Synthesis 2002, 1293.

[14] a) J. J. Lavigne, D. L. Broughton, J. N. Wilson, B. Erdogan, U. H. F. Bunz, Macromolecules 2003, 36, 7409. b) C. Tan, E. Atas, J. G. Müller, M. R. Pinto, V. D. Kleiman, K. S. Schanze, J. Am. Chem. Soc. 2004 126, 13685. c) M. Stork, B. S. Gaylord, A. J. Heeger, G. C. Bazan, Adv. Mater. 2002, 14, 361. d) ref. 12(b).

[15] K. Lee, J. C. Cho, J. DeHeck, J. Kim, Chem. Commun. 2006, 1983.

[16] a) H. A. Ho, K. Doré, M. Boissinot, M. G. Bergeron, R. M. Tanguay, D. Boudreau, M. Leclerc, J. Am. Chem. Soc. 2005, 127, 12673 b) M. Béra-Abérem, A. Najari, H.-A. Ho, J.-F. Gravel, P. Nobert, D. Boudreau, M. Leclerc, Adv. Mater. 2006, 18, 2703. c) H.-A. Ho, M. Béra-Abérem, M. Leclerc, Chem. Eur. J. 2005, 11, 1718.

[17] a) ref. 11(b). b) B. S. Gaylord, A. J. Heeger, G. C. Bazan, J. Am. Chem. Soc. 2003, 125, 896. c) B. Liu, G. C. Bazan, Chem. Mater. 2004 16, 4467.

[18] C. J. Yang, M. Pinto, K. Schanze, W. Tan, Angew. Chem. Int. Ed. 2005 $44,2572$.

[19] a) See ref. 7(a). b) See, ref. 15. c) A. Khan, S. Müller, S. Hecht, Chem. Commun. 2005, 584

[20] a) See ref. 14(a). b) L. Chen, S. Xu, D. McBranch, D. Whitten, J. Am. Chem. Soc. 2000, 122, 9302. c) H. D. Burrows, V. M. M. Lobo, J. Pina, M. L. Ramos, J. Seixas de Melo, A. J. M. Valente, M. J. Tapia, S. Pradhan, U. Scherf, Macromolecules 2004, 37, 7425. d) M. J. Tapia, H. D. Burrows, A. J. M. Valente, S. Pradhan, U. Scherf, V. M. M. Lobo, J. Pina, J. Seixas de Melo, J. Phys. Chem. B 2005, 109, 19108. e) See ref. 18 .

[21] a) C. Tan, M. R. Pinto, K. S. Schanze, Chem. Commun. 2002, 446. b) M. R. Pinto, B. M. Kristal, K. S. Schanze, Langmuir 2003, 19, 6523.

[22] a) see ref. 15. b) D.-L. Jiang, C.-K. Choi, K. Honda, W.-S. Li, T. Yuzawa, T. Aida, J. Am. Chem. Soc. 2004, 126, 12 084. c) see ref. 19(c).

[23] a) T. Förster, Ann. Phys. 1948, 2, 55. b) J. R. Lakowicz, Principles of Fluorescence Spectroscopy, Kluwer Academic/Plenum Publisher, New York 1999.

[24] There was a slight red-shift of the emission maxima of HEX from $\lambda=555 \mathrm{~nm}$ without the polymer donor molecule to $\lambda=561 \mathrm{~nm}$ when HEX complexed with the polymer. A change in the charge density around HEX due to the close proximity of the negatively charged polymer induces a polarity change in the HEX molecule and likely causes the red-shift.

[25] a) C. A. M. Seidal, A. Schulz, M. H. M. Sauer, J. Phys. Chem. 1996 100, 5541. b) S. A. E. Marras, F. R. Kramer, S. Tyagi, Nucleic Acids Res. 2002, 30, e122. c) S. Steenken, V. Jovanovic, J. Am. Chem. Soc. 1997, 119, 617. d) T. Heinlein, J.-P. Knemeyer, O. Piestert, M. Sauer, $J$. Phys. Chem. B 2003, 107, 7957.

[26] a) G. Bonnet, S. Tyagi, A. Libchaber, F. R. Kramer, Proc. Natl. Acad. Sci. USA 1999, 96, 6171. b) S. A. E. Marras, F. R. Kramer, S. Tyagi, Nucleic Acids Res. 2002, 30, e122. c) S. Tyagi, D. P. Bratu, F. R. Kramer, Nat. Biotechnol. 1998, 16, 49. d) S. Tyagi, S. A. E. Marras, F. R. Kramer, Nat. Biotechnol. 2000, 18, 1191

[27] T. Antony, V. Subramaniam, J. Biomol. Struct. Dyn. 2001, 19, 497.

[28] a) M. Zuker, Nucleic Acids Res. 2003, 31, 3406. b) D. H. Mathews, J. Sabina, M. Zuker, D. H. Turner, J. Mol. Biol. 1999, 288, 911. 